\title{
Kollege schlampte bei Leichenschau
}

\section{Sieht so ein Herzstillstand aus?}

\begin{abstract}
Klarer Fall, dachte sich der nachts zu dem Leichnam hinzugezogene Arzt und stellte den Totenschein aus: Typischer Herzstillstand bei chronischem Alkoholmissbrauch ... Hätte er dem 27-Jährigen wenigstens mal unter den Kragen geschaut, wäre dem Arzt die peinliche Fehldiagnose erspart geblieben.
\end{abstract}

Denn die Krematoriumsleichenschau brachte schnell ans Licht, was offensichtlich war: Eine typische Strangmarke (• Abb. 1) mit horizontalem Verlauf und zahlreichen Stauungsblutungen im Gesicht ( Abb. 3) - deutlicher kann ein Toter kaum zeigen, dass er erwürgt worden ist, schreibt Dr. Ralf F. Zweihoff, Dortmund, in der Zeitschrift „Rechtsmedizin“. Doch wie konnte der nächtlich herbeigezogene Arzt unter diesen Umständen einen „natürlichen Tod“ bescheinigen? Ganz einfach: Der Grund dafür ist am Körper des Mannes ebenso abzulesen wie die Strangmarke: Die Leichenfleckaussparungen $(\bullet$ Abb. 2) durch die postmortal anliegende Kleidung sind ein Hinweis darauf, dass der Körper zur Leichenschau nicht entkleidet worden war.
Nach der Entdeckung im Krematorium kam die Kripo auf den Plan. Der Leichnam wurde in der Rechtsmedizin seziert, und alle Befunde deckten sich mit dem Strangulationsverdacht. Zudem war der Mann schwer alkoholisiert gewesen. 3,02 Promille im Blut und 4,13 im Urin deuteten auf einen nicht unbeträchtlichen Alkoholkonsum hin.

\section{Verzweifelte Mutter am Werk}

Nun, da der Fall ins Rollen gekommen war, kam es recht schnell zur Aufklärung desselben. Die wegen des chronischen Alkoholmissbrauchs und der Gewalttätigkeit tief verzweifelte Mutter hatte ihren eigenen Sohn mit einem längs aus Bettlaken zugeschnittenen und

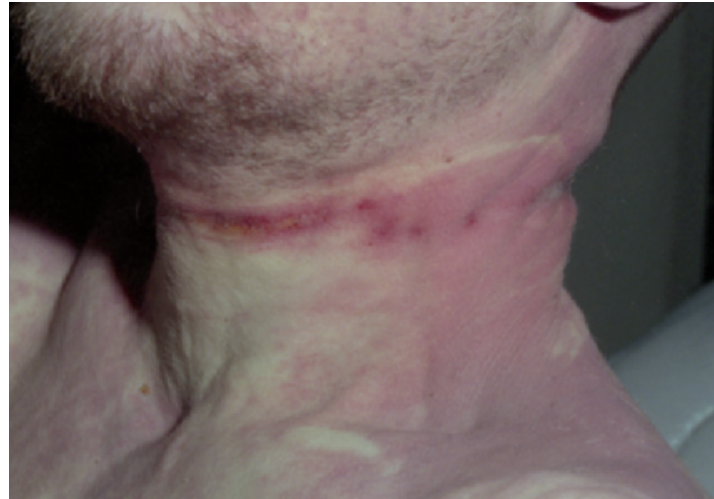

Abb. 1 Links am Hals die teilweise durchbrochene Strangulationsmarke.

als Putzlappen verwendeten Stoffstreifen erdrosselt, als dieser hochalkoholisiert auf dem Sofa eingeschlafen war. Die geständige Frau wurde wegen Totschlag in einem minderschweren Fall verurteilt.

\section{Wurde der Verstorbene überhaupt untersucht?}

Skandalös ist dieser Fall aus einem anderen Grund: Die Fehlleistung des die Leichenschau durchführenden Arztes ist nur dadurch erklärlich, dass er den Verstorbenen außerordentlich oberflächlich, wenn überhaupt, untersucht hat, so Dr. Zweihoff. Denn die Hinweise auf ein Strangulationsgeschehen waren eigentlich unübersehbar. (Sonja Kempinski) Rechtsmedizin 2009; 19(6):428

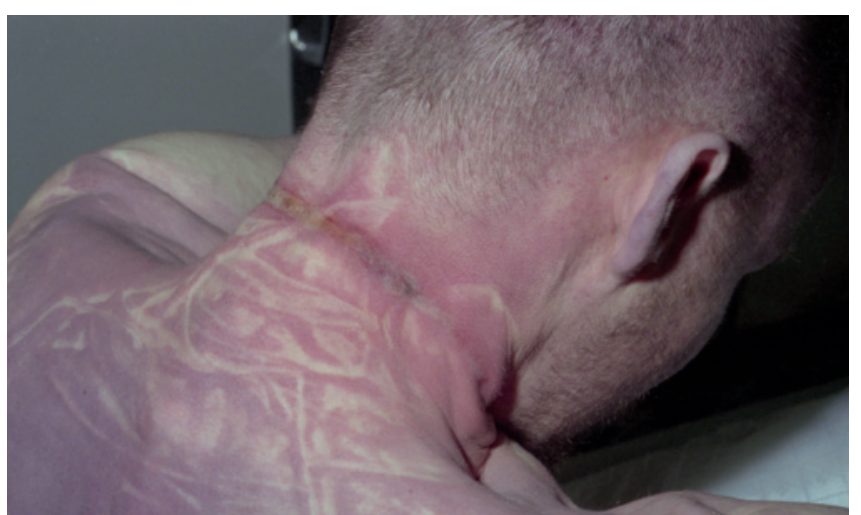

Abb. 2 Im Nacken horizontaler Verlauf der Strangmarke. Gut sichtbar auch die Leichenfleckaussparungen durch hier postmortal anliegende Kleidung als Hinweis darauf, dass die Leiche zur Leichenschau nicht entkleidet wurde.

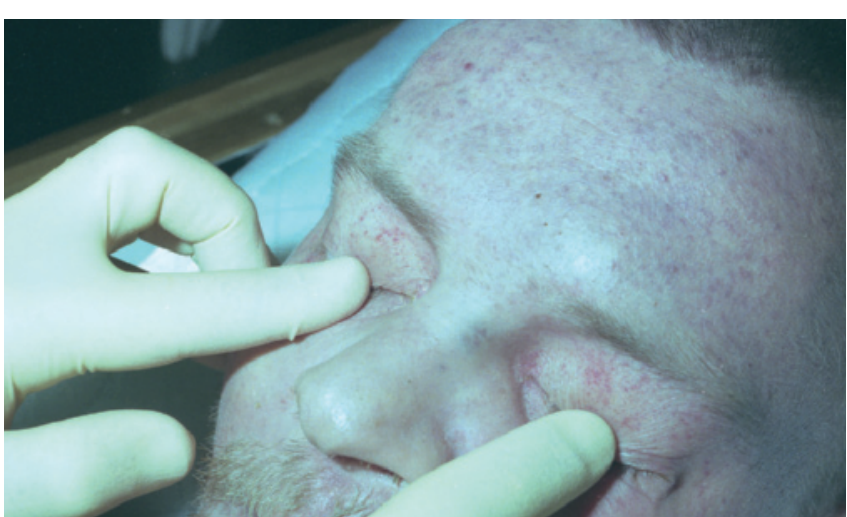

Abb. 3 Petechiale Blutungen außen auf den Augenlidern werden durch Straffung der Oberlider sichtbar. 